\title{
$\mathrm{Ni} / \mathrm{Ru}-\mathrm{K} / \mathrm{Al}_{2} \mathrm{O}_{3}$ 촉매를 이용한 톨루엔 수증기 개질

\author{
오건웅 ${ }^{1} \cdot$ 박서윤 $^{2} \cdot$ 이재구 $^{3} \cdot$ 윤상준 $^{1,3 \dagger}$
} \\ ${ }^{1}$ 과학기술연합대학원대학교 신에너지기술, ${ }^{2}$ 충북대학교 환경공학과, ${ }^{3}$ 한국에너지기술연구원 기후변화연구본부
}

\section{Steam Reforming of Toluene over $\mathrm{Ni} / \mathrm{Ru}-\mathrm{K} / \mathrm{Al}_{2} \mathrm{O}_{3}$ Catalyst}

KUN WOONG OH ${ }^{1}$, SEO YOON PARK ${ }^{2}$, JAE GOO LEE ${ }^{3}$, SANG JUN YOON ${ }^{1,3 \dagger}$

\author{
${ }^{1}$ Advanced Energy Technology, University of Science and Technology, Daejeon, Republic of Korea \\ ${ }^{2}$ Department of Environmental Engineering, Chungbuk National University, Cheongju, Republic of Korea \\ ${ }^{3}$ Climate Change Research Division, Korea Institute of Energy Research, Daejeon, Republic of Korea
}

\begin{abstract}
The catalytic steam reforming of toluene, a major component of biomass tar, was studied using several catalysts at various temperatures $400-800^{\circ} \mathrm{C}$, kind of metal, and metal loading content. Ru and $\mathrm{K}$ promoted Ni-base catalyst were prepared, and used for steam reforming of toluene with steam/toluene molar ratio of 25 . Concentration of toluene in reactant flow is $30 \mathrm{~g} / \mathrm{Nm}^{3}$ that is usual content of tar from biomass gasifier. The result from experiments showed that $\mathrm{H}_{2}$ content in product gas and toluene conversion increased with temperature. Where in high temperature range, $\mathrm{CO}$ and $\mathrm{CO}_{2}$ content in product gas were affected mainly by Boudouard reaction. Ni/Ru-K $(3 \mathrm{wt} \%) / \mathrm{Al}_{2} \mathrm{O}_{3}$ catalyst showed best performance on steam reforming of toluene than used catalysts in this study at whole temperature. Catalysts have been characterized by XRD, TG. XRD analysis displayed that Ni particle size on $\mathrm{Ni} / \mathrm{Ru}-\mathrm{K}(3 \mathrm{wt} \%) / \mathrm{Al}_{2} \mathrm{O}_{3}$ catalyst was $29.4 \mathrm{~nm}$. Activation energy of $\mathrm{Ni} / \mathrm{Ru}-\mathrm{K}(3 \mathrm{wt} \%) / \mathrm{Al}_{2} \mathrm{O}_{3}$ catalyst was calculated $36.8 \mathrm{~kJ} / \mathrm{mol}$ by Arrhenius plot.
\end{abstract}

Key words : Steam reforming(수증기 개질), Toluene(톨루엔), Biomass tar(바이오매스 타르), Gasification(가스 화), Syngas(합성가스)

\section{1. 서 론}

지구 온난화와 유가 상승 등으로 인해 기존의 화 석연료에 대한 의존도를 줄이려는 노력은 계속되고 있다. ${ }^{1)}$ 이러한 노력 중 하나로 온실가스를 줄이고 에 너지원의 다양성을 늘리고자 신재생에너지에 대한 연구가 지속되고 있으며, 특히 신재생에너지 중의 하 나인 바이오매스는 지역에 편중적이지 않고 생장기

\footnotetext{
${ }^{\dagger}$ Corresponding author : yoonsj@kier.re.kr [ 접수일 : 2014.09.30 수정일 : 2014.10.15 게재확정일 : 2014.10 .31 ] Copyright (c) 2014 KHNES
}

간 동안 $\mathrm{CO}_{2}$ 를 소비하므로 화석연료를 대체할 에너 지원으로 주목받고 있다 ${ }^{2,3)}$.

가스화는 이러한 바이오매스를 원료로 사용하는 유용한 방법 중 하나로 ${ }^{4-6}$, 열에너지 사용은 물론 부 분산화를 통하여 합성가스 생성, 전력생산 및 여러 화 학 물질의 합성 등 다양한 분야에 적용할 수 있다 ${ }^{7-9)}$. 바이오매스의 가스화 시 합성가스와 함께 탄화수 소로 이루어진 타르가 생성되며 이는 엔진이나 파이 프 등에 부착되어 공정에 심각한 문제를 일으킨다 ${ }^{10)}$. 따라서 타르를 제거하기 위한 방법이 연구되어 왔으 며 그 중 촉매를 이용한 수증기 개질은 타르 제거와 
함께 $\mathrm{H}_{2}$ 와 $\mathrm{CO}$ 를 생산할 수 있는 장점이 있어 주목받 고 있다 ${ }^{11)}$.

수증기 개질을 위한 촉매로 $\mathrm{Ru}, \mathrm{Pt}$ 와 같은 귀금 속 촉매, Ni-base 촉매 등이 사용되었으며 ${ }^{12)}$ olivine, dolomite 등의 광물도 타르 수증기 개질에 효과가 있 는 것으로 알려져 있다 ${ }^{4,11)}$. 메탄이나 나프타 등의 탄 화수소 수증기 개질에 쓰이는 $\mathrm{Ru}, \mathrm{Pt}$ 등 귀금속은 타 르 수증기 개질에서도 높은 활성을 보이며 탄소 침 적에도 강한 저항성을 보인다, ${ }^{9,13)}$. 그러나 높은 비용 은 공정 적용에 경제적인 문제가 된다. 이러한 문제 를 해결하기 위해 귀금속의 함량을 낮추어 비용을 감소시키고 $\mathrm{Mg}, \mathrm{K}$ 등 촉진제를 첨가하면 촉매의 활 성과 내구성이 향상된다 ${ }^{9}$.

$\mathrm{Co}, \mathrm{Fe}$ 와 더불어 탄화수소 수증기 개질에 많이 사 용되는 $\mathrm{Ni}$ 는 높은 활성과 $\mathrm{Ru}, \mathrm{Pt}$ 등의 귀금속에 비해 상대적으로 적은 비용이 요구되어 촉매로써 유용하 다 ${ }^{1,712)}$. 그러나 Tammann temperature ${ }^{12)}$ 이상에서는 $\mathrm{Ni}$ 입자가 소결되어 활성이 저하되며 반응이 진행 될 수록 탄소 침적(coking)이 발생하여 활성 저하 및 촉 매의 흐름이 막히는 현상이 일어나게 된다 ${ }^{12,14)}$. 따라 서 소결 및 탄소 침적을 해결하기 위해 첨가되는 촉 진제와 촉매의 구조에 대한 연구가 진행되어왔다. $\mathrm{Na}^{9,15}$ 과 같은 알칼리 금속, $\mathrm{Ca}, \mathrm{Sr}$ 과 같은 알칼리 토 금속 ${ }^{2,916)}$ 이 촉진제로 효과 있는 것으로 알려져 있으 며, $\mathrm{La}$ 과 란탄족의 $\mathrm{Ce}$ 는 촉매 구조 내 산소의 이동과 저장을 도와 활성과 탄소 침적 저항성을 향상시킨다 ${ }^{1,7)}$.

촉매의 지지체에 대한 연구도 진행되어 함침법에 서는 $\mathrm{a}-, \gamma-\mathrm{Al}_{2} \mathrm{O}_{3}$ 등이 사용되며, $\mathrm{a}-\mathrm{Al}_{2} \mathrm{O}_{3}$ 이 $\gamma-\mathrm{Al}_{2} \mathrm{O}_{3}$ 에 비해 상대적으로 비표면적이 작으나 고온에서 안 정성이 좋아, 타르 수증기 개질에 적합한 것으로 알 려진다 ${ }^{17)}$.

본 연구에서는 바이오매스 타르의 주요 구성 물질 중 하나인 톨루엔을 모사타르로 사용하여 수증기 개 질을 수행하였다. 톨루엔의 농도는 바이오매스 가스 화 시 발생되는 타르 농도 $5-75 \mathrm{~g} / \mathrm{Nm}^{3}$ 의 범위에 속
하는 $30 \mathrm{~g} / \mathrm{Nm}^{3}$ 을 선정하였다 ${ }^{4)}$ 촉매 제작을 위해 탄 화수소 개질에 많이 쓰이는 $\mathrm{Ni}$ 을 활성 물질로 사용 하고 톨루엔 수증기 개질은 고온 영역의 반응도 요 구되므로 고온에서 안정성 있는 $\mathrm{a}-\mathrm{Al}_{2} \mathrm{O}_{3}$ 를 지지체로 사용하였다. 촉매 활성 증가와 탄소 침적 저항성 향 상을 위해 $\mathrm{Ru}$ 와 $\mathrm{K}$ 를 첨가하고 톨루엔 수증기 개질 결과를 비교하여 각 촉진제의 효과와 톨루엔 수증기 개질에 가장 좋은 활성을 보이는 촉매를 관찰하였다. 각 촉매의 $\mathrm{Ni}$ 입자 크기와 탄소 침적양을 측정하기 위해 $\mathrm{XRD}, \mathrm{TG}$ 분석을 수행하여 촉매의 활성 및 내 구성을 확인하였다. 이후 톨루엔 수증기 개질의 결과 로 $\mathrm{E}_{\mathrm{a}}$ 값을 계산하여 앞선 톨루엔 수증기 개질 실험의 결과와 비교하였다.

\section{2. 실 험}

\section{1 촉매 제조}

실험에 쓰인 톨루엔 수증기 개질 촉매의 조성은 Table. 1과 같다. 촉매 제작을 위해, Nickel nitrate hexahydrate $\left(\mathrm{Ni}\left(\mathrm{NO}_{3}\right)_{2} \cdot 6 \mathrm{H}_{2} \mathrm{O}\right.$, JUNSEI), Ruthenium chloride hydrate $\left(\mathrm{RuCl}_{2} \cdot \mathrm{xH}_{2} \mathrm{O}\right.$, Aldrich), Potassium nitrate $\left(\mathrm{KNO}_{3}\right.$, Alfa Aesar)를 함침법을 이용하여 a-alumina $\left(\mathrm{Al}_{2} \mathrm{O}_{3}, \mathrm{Alfa}\right.$ Aesar)에 각각의 조성 별로 담지하였다. 담지된 촉매는 건조 오븐에서 24 시간 건조한 후, $2^{\circ} \mathrm{C} /$ $\min$ 의 승온 속도로 $800^{\circ} \mathrm{C}$ 에서 3 시간동안 소성하였다.

\section{2 실험 장치 및 방법}

Fig. 1은 실험실 규모의 타르 수증기 개질을 위한 시스템의 장치도이다. 온도 조절을 위해 furnace를

Table. 1 Chemical composition of catalysts

\begin{tabular}{c|c|c|c}
\hline \hline 촉 매 & 활성 물질 & 촉진제 & 지지체 \\
\hline $\mathrm{Ni} / \mathrm{Al}_{2} \mathrm{O}_{3}$ & $\mathrm{Ni} 20 \mathrm{wt} \%$ & - & $\mathrm{a}-\mathrm{Al}_{2} \mathrm{O}_{3}$ \\
\hline $\mathrm{Ni} / \mathrm{Ru} / \mathrm{Al}_{2} \mathrm{O}_{3}$ & $\mathrm{Ni} 20 \mathrm{wt} \%$ & $\mathrm{Ru} 0.6 \mathrm{wt} \%$ & $\mathrm{a}-\mathrm{Al}_{2} \mathrm{O}_{3}$ \\
\hline $\mathrm{Ni} / \mathrm{Ru}-\mathrm{K} / \mathrm{Al}_{2} \mathrm{O}_{3}$ & $\mathrm{Ni} 20 \mathrm{wt} \%$ & $\mathrm{Ru} 0.6 \mathrm{wt} \%, \mathrm{~K} 1,3 \mathrm{wt} \%$ & $\mathrm{a}-\mathrm{Al}_{2} \mathrm{O}_{3}$ \\
\hline
\end{tabular}




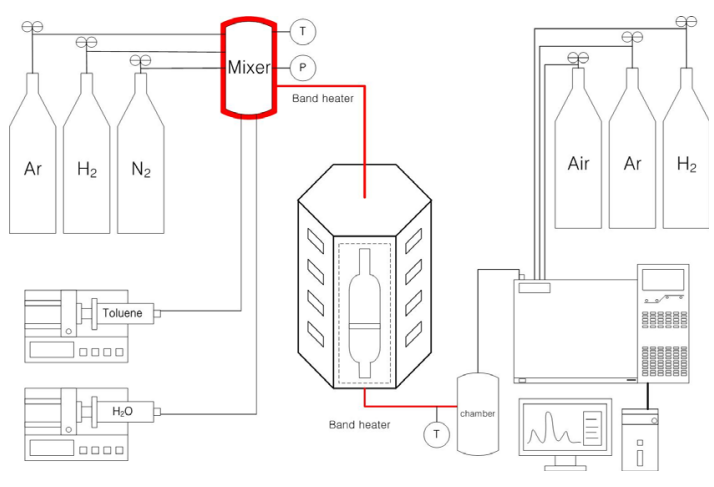

Fig. 1 Schematic diagram of steam toluene reforming system

설치하였고, 내부의 반응기는 폭 $20 \mathrm{~mm}$, 길이 $520 \mathrm{~mm}$

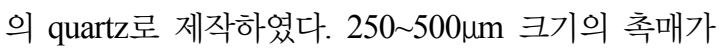
반응기 중간에 위치하게 되며 공간속도(gas hourly space velocity, GHSV) $10,000 \mathrm{~h}^{-1}$ 를 기준으로 촉매의 양을 결정하였다. 톨루엔의 농도는 $30 \mathrm{~g} / \mathrm{Nm}^{3}$, 스팀과 톨루엔의 몰 비(steam/fuel)는 25로 일정하게 유지하 도록 각각 피스톤 펌프로 주입하였다. 각각의 공급 라인은 밴드히터로 $250{ }^{\circ} \mathrm{C}$ 로 유지하여 기체 상태로 반응기로 공급되도록 하였다. 운반 기체인 질소는 $\mathrm{MFC}$ 를 이용하여 $40.50 \mathrm{~mL} / \mathrm{min}$ 으로 주입하고, gas mixer에서 질소와 기화된 톨루엔, 스팀이 만나 섞인 후 반응기에 주입되었다. 온도 관찰을 위해 K-type 열전쌍을 반응기 내부와 gas mixer에 설치하였고 압 력 관찰을 위해 반응물 주입관에 압력계를 설치하였 다. 제작한 촉매들은 실험 전 $\mathrm{H}_{2} / \mathrm{Ar}=1: 1,50 \mathrm{~mL} / \mathrm{min}$ 유량으로 $800^{\circ} \mathrm{C}$ 에서 2 시간 동안 환원하였다.

반응기를 통과한 미반응 톨루엔과 스팀은 반응기 하단에 위치한 chamber에서 액상으로 포집하였고, 생성된 가스는 gas chromatography(HP 6890)로 유입 되어, $\mathrm{TCD}$ 와 $\mathrm{FID}$ 를 이용하여 분석하였다. 톨루엔의 전환율 $\left(\mathrm{X}_{\mathrm{c}}\right)$ 은 다음 식으로 계산하였다.

$$
X_{c}=\frac{V_{C O}+V_{C H_{4}}+V_{C O_{2}}}{7 \times V_{C_{7} H_{8}}} \times 100
$$

$\mathrm{GC}$ 에서 분석한 질소로 전체 유량을 계산하여 각
기체의 몰 유량 $\mathrm{V}$ 를 계산하였다.

\section{3 촉매 특성 분석}

촉진제 첨가에 따른 $\mathrm{Ni}$ 입자 크기 측정을 위해 $\mathrm{X}$ 선 회절(X-ray diffraction) 분석을 Rigaku smartlab 장비로 수행하였다. 각각의 촉매에 대한 $\mathrm{X}$ 선 회절 분석 후 Scherrer equation을 이용하여 촉매의 $\mathrm{Ni}$ 입 자 크기를 계산하였다. 톨루엔 수증기 개질 실험 후, 촉매의 탄소 침적양 측정을 위해 열중량 분석(thermogravimetric analysis, TGA)을 수행하였다. $400-800^{\circ} \mathrm{C}$ 까지 9시간 동안 실험한 촉매를 회수하여, 약 $10 \mathrm{mg}$ 의 시료를 $10^{\circ} \mathrm{C} / \mathrm{min}$ 으로 $1000^{\circ} \mathrm{C}$ 까지 승온하며 질량 의 변화를 Mettler-toledo 1600LF장비로 측정하였다.

\section{3. 결과 및 토의}

\section{1 톨루엔의 수증기 개질 반응 특성}

톨루엔 수증기 개질에서 $\mathrm{Ru}, \mathrm{K}$ 각각 촉진제의 효 과를 확인하기 위해 실험을 수행하였다. 촉진제를 첨 가하기에 앞서 촉매별 전환율과 생성가스 조성의 비 교를 위해 먼저 $\mathrm{Ni} / \mathrm{Al}_{2} \mathrm{O}_{3}$ 촉매를 온도별로 실험하여 Fig. 2에 나타내었다.

반응기 내 온도가 상승함에 따라 전환율이 증가하 였고 $800^{\circ} \mathrm{C}$ 에서 $88 \%$ 의 전환율을 보였다. 생성가스 내 $\mathrm{H}_{2}$ 생성량은 지속적인 증가를 보이며 $800^{\circ} \mathrm{C}$ 에서 $0.1425 \mathrm{~mol} / \mathrm{g}_{\mathrm{tar}}$ 가 생성되었다. 저온에서는 $\mathrm{H}_{2}$ 생성량 이 크게 증가하였으나 $600^{\circ} \mathrm{C}$ 이상의 고온에서는 증 가량이 감소하며 거의 수렴하는 것이 관찰되었다. 반 응기 온도와 함께 $\mathrm{CO}$ 의 생성량은 지속적으로 증가 하였고 $\mathrm{CH}_{4}$ 는 다른 문헌의 결과와 같이 극소량 검출 되었다 ${ }^{12)} . \mathrm{CO}_{2}$ 는 $600^{\circ} \mathrm{C}$ 이하에서 생성량이 증가하였 으나 $600^{\circ} \mathrm{C}$ 에서 최대값 $0.0391 \mathrm{~mol} / \mathrm{g}_{\mathrm{tar}}$ 생성 후 다시 감소하는 경향을 보였다.

톨루엔 수증기 개질에서 $\mathrm{Ru}$ 의 효과를 확인하기 


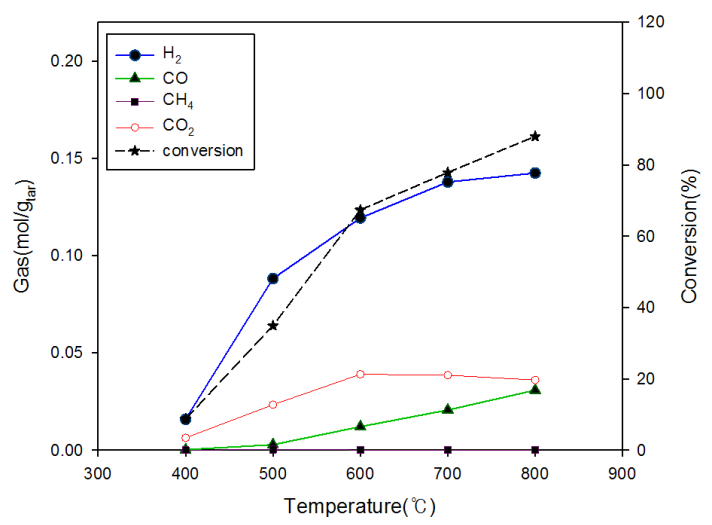

Fig. 2 Variation of product gas composition and toluene conversion over $\mathrm{Ni}(20 \mathrm{wt} \%)$ catalyst(steam/toluene ratio $=25$, $\mathrm{GHSV}=10,000^{-1}$ )

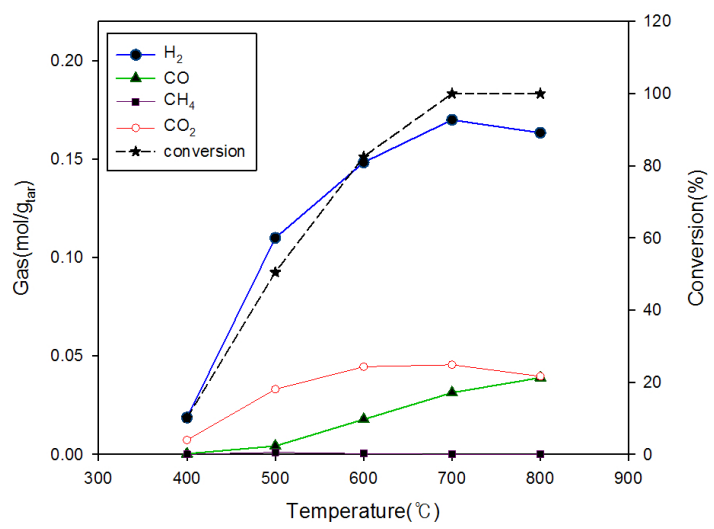

Fig. 3 Variation of product gas composition and toluene conversion over $\mathrm{Ni}(20 \mathrm{wt} \%) / \mathrm{Ru}(0.6 \mathrm{wt} \%)$ catalyst(steam/toluene ratio $=25, \mathrm{GHSV}=10,000^{-1}$ )

위해 $\mathrm{Ni}(20 \mathrm{wt} \%)$ 에 $\mathrm{Ru}(0.6 \mathrm{wt} \%)$ 를 첨가한 촉매의 반 응 온도에 따른 실험 결과를 Fig. 3에 나타내었다. 톨 루엔의 전환율은 반응기 내 온도가 상승함에 따라 지속적으로 증가하여 $700^{\circ} \mathrm{C}$ 에서 $100 \%$ 에 도달하였으 며 Fig. 2의 $\mathrm{Ni} / \mathrm{Al}_{2} \mathrm{O}_{3}$ 촉매보다 전 온도영역에서 전 환율이 증가하였다. 생성가스 내 $\mathrm{H}_{2}$ 의 생성량은 온 도 상승과 함께 지속적으로 증가하여 $700^{\circ} \mathrm{C}$ 에서 $0.17 \mathrm{~mol} / \mathrm{g}_{\mathrm{tar}}$ 가 생성되었으며 이후 Fig. 2와 같이 거의 수렴하는 경향을 보였다. $\mathrm{CO}$ 와 $\mathrm{CO}_{2}$ 의 생성량도 Fig. 2 의 $\mathrm{Ni} / \mathrm{Al}_{2} \mathrm{O}_{3}$ 촉매와 유사한 경향을 보였으며 $\mathrm{CO}_{2}$ 는 $600^{\circ} \mathrm{C}$ 에서 $0.0445 \mathrm{~mol} / \mathrm{g}_{\text {tar }}$ 가 생성되었다.

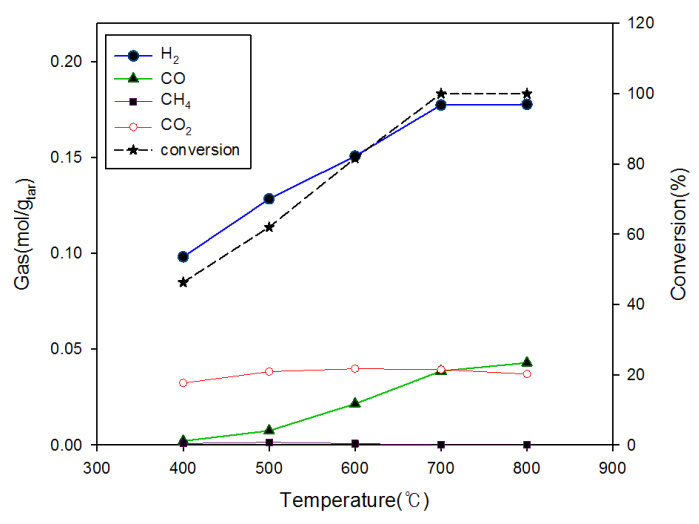

Fig. 4 Variation of product gas composition and toluene conversion over $\mathrm{Ni}(20 \mathrm{wt} \%) / \mathrm{Ru}(0.6 \mathrm{wt} \%)-\mathrm{K}(1 \mathrm{wt} \%)$ catalyst(steam/ toluene ratio $=25, \mathrm{GHSV}=10,000^{-1}$ )

Fig. 2와 3의 결과로 보았을 때, 톨루엔 수증기 개 질에서 $\mathrm{Ru}$ 의 첨가로 인하여 촉매 활성의 증가가 관 찰되었다. $800^{\circ} \mathrm{C}$ 에서 최대 $88 \%$ 의 전환율을 보이는 $\mathrm{Ni} / \mathrm{Al}_{2} \mathrm{O}_{3}$ 촉매와 달리 $\mathrm{Ni} / \mathrm{Ru} / \mathrm{Al}_{2} \mathrm{O}_{3}$ 촉매는 $700^{\circ} \mathrm{C}$ 에 서 $100 \%$ 전환율을 나타내었고 낮은 온도영역에서도 전환율의 증가가 이루어졌다. 바이오매스 가스화 시 생성되는 합성가스의 온도를 고려해 볼 때 낮은 개 질 온도에서의 높은 전환율이 요구되며, 합성가스를 이용한 전력 생산을 위해서는 전환율 $100 \%$ 에 가까 운 매우 적은 양의 타르가 허용된다 ${ }^{18)}$. 따라서 톨루 엔 수증기 개질 촉매의 촉진제로 $\mathrm{Ru}$ 가 적합하다는 것을 알 수 있다.

앞서 확인한 $\mathrm{Ru}$ 의 성능에 더불어 촉진제로서 $\mathrm{K}$ 의 톨루엔 수증기 개질에서 효과를 확인하고 $\mathrm{K}$ 의 함량 에 따른 변화를 관찰하기 위해 실험을 수행하였다.

Fig. 4는 Ni/Ru-K(1wt\%)/ $\mathrm{Al}_{2} \mathrm{O}_{3}$ 촉매의 톨루엔 수 증기 개질 실험 결과이다. 전환율은 Fig. 3 의 Ni/Ru/ $\mathrm{Al}_{2} \mathrm{O}_{3}$ 촉매 실험과 유사한 경향을 보이며 $700^{\circ} \mathrm{C}$ 에서 전환율 $100 \%$ 에 도달하였다. 그러나 $500^{\circ} \mathrm{C}$ 이하의 낮 은 온도영역에서 $\mathrm{Ni} / \mathrm{Ru} / \mathrm{Al}_{2} \mathrm{O}_{3}$ 촉매보다 더 높은 전 환율이 관찰되었고 특히 $400^{\circ} \mathrm{C}$ 에서 $46 \%$ 의 전환율을 나타내며 높은 활성을 보여주었다. 생성가스 내 $\mathrm{H}_{2}$ 와 $\mathrm{CO}$ 는 온도가 상승함에 따라 생성량이 지속적으 


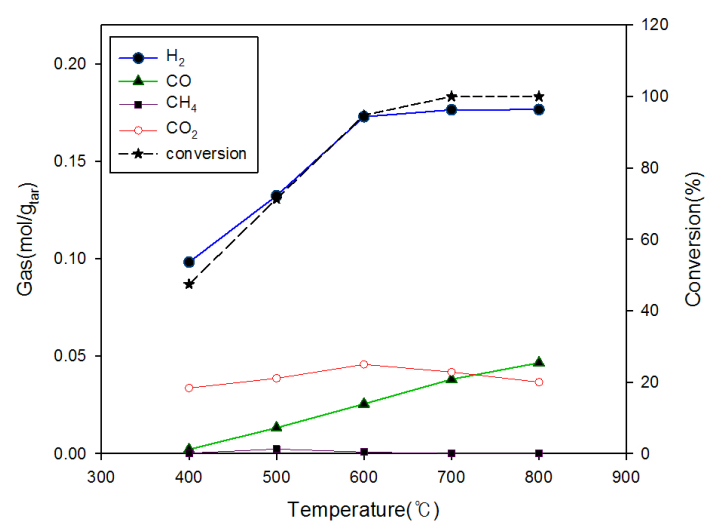

Fig. 5 Variation of product gas composition and toluene conversion over $\mathrm{Ni}(20 \mathrm{wt} \%) / \mathrm{Ru}(0.6 \mathrm{wt} \%)-\mathrm{K}(3 \mathrm{wt} \%)$ catalyst(steam/ toluene ratio $=25, \mathrm{GHSV}=10,000^{-1}$ )

로 증가하는 경향을 보였으며 $\mathrm{H}_{2}$ 는 $700 ~ 800^{\circ} \mathrm{C}$ 에서 $0.177 \mathrm{~mol} / \mathrm{g}_{\mathrm{tar}}$ 에 수렴하였다. $\mathrm{CO}_{2}$ 의 생성량은 반응 온 도 따라 작은 변화를 보이며 Fig. 2와 3과 같이 60 $0^{\circ} \mathrm{C}$ 에서 최대값이 관찰되었다.

Fig. 5는 K의 함량을 3 배 높인 Ni/Ru-K(3wt\%)/ $\mathrm{Al}_{2} \mathrm{O}_{3}$ 촉매의 톨루엔 수증기 개질 결과이다. 반응기 내 온도가 상승함에 따라 톨루엔 전환율이 증가하였 고 Fig. 3, 4와 동일하게 $700^{\circ} \mathrm{C}$ 에서 $100 \%$ 전환율에 도달하였다. 그러나 적은 $\mathrm{K}$ 함량 $(1 \mathrm{wt} \%)$ 의 실험 결과 인 Fig. 4 보다 $500 \sim 600^{\circ} \mathrm{C}$ 에서 높은 전환율이 관찰되 었으며, 이것은 촉매의 $\mathrm{K}$ 함량이 촉매 활성에 영향 을 주는 것으로 판단된다. 앞서 언급했듯이 바이오매 스 가스화기에서 생성되는 합성가스의 온도를 고려 할 때 낮은 온도에서의 톨루엔 전환율은 중요하다. 따라서 $\mathrm{Ru}$ 과 $\mathrm{K}$ 가 첨가된 $\mathrm{Ni} / \mathrm{Ru}-\mathrm{K}(3 \mathrm{wt} \%) / \mathrm{Al}_{2} \mathrm{O}_{3}$ 촉매 는 실험에 쓰인 촉매 중 가장 좋은 활성을 보이며 낮 은 온도에서도 높은 활성을 보이는, 톨루엔 수증기 개질에 적합함을 알 수 있다.

생성가스 내 $\mathrm{H}_{2}, \mathrm{CO}, \mathrm{CO}_{2}$ 의 변화는 Fig. 3,4 와 유 사한 경향을 보였다. $\mathrm{H}_{2}$ 의 생성량은 온도 상승에 따 라 증가 후 전환율이 일정해지는 $700^{\circ} \mathrm{C}$ 에서 수렴하 는 것이 관찰되었다. $\mathrm{CO}$ 의 생성량은 온도 증가에 따 라 지속적으로 증가하였으며, $\mathrm{CO}_{2}$ 는 $600^{\circ} \mathrm{C}$ 까지 생성
량이 증가한 뒤 높은 온도의 영역에서는 생성량이 감소하였다.

Fig. 2, 3, 4, 5의 톨루엔 수증기 개질 시 발생하는 대표적인 반응은 다음과 같다 ${ }^{1,12,19)}$.

$$
\begin{aligned}
& \text { Steam reforming } \\
& \mathrm{C}_{7} \mathrm{H}_{8}+7 \mathrm{H}_{2} \mathrm{O} \rightarrow 7 \mathrm{CO}+11 \mathrm{H}_{2} \\
& \mathrm{C}_{7} \mathrm{H}_{8}+14 \mathrm{H}_{2} \mathrm{O} \rightarrow 7 \mathrm{CO}_{2}+18 \mathrm{H}_{2}
\end{aligned}
$$

톨루엔이 steam과 만나 각각 $\mathrm{H}_{2}, \mathrm{CO}, \mathrm{CO}_{2}$ 가 생성 되는 반응으로써 온도와 steam/toluene ratio의 영향 을 받는다,12). 반응이 진행되면 $\mathrm{CO}, \mathrm{CO}_{2}$ 로 인해 전 환율이 증가하게 되고 $\mathrm{H}_{2}$ 의 생성량이 증가하게 된다. 이때 식 (2)와 (3)에서 반응하는 톨루엔 $\mathrm{mol}$ 당 $\mathrm{H}_{2}$ 생 성량이 제일 크며, 이것은 Fig. 2, 3, 4, 5의 톨루엔 수 증기 개질 시 생성가스 내 $\mathrm{H}_{2}$ 의 생성량이 가장 많은 것을 설명해 준다.

Hydroalkylation

$$
\mathrm{C}_{7} \mathrm{H}_{8}+\mathrm{H}_{2} \rightarrow \mathrm{C}_{6} \mathrm{H}_{6}+\mathrm{CH}_{4}
$$

Methane steam reforming

$$
\mathrm{CH}_{4}+\mathrm{H}_{2} \mathrm{O} \rightleftharpoons \mathrm{CO}+3 \mathrm{H}_{2}
$$

$\mathrm{CH}_{4}$ 는 식 (4)와 (5)에 의해 생성되고 소비된다. 그 러나 문헌 ${ }^{12)}$ 과 앞선 실험결과에서 확인되었듯이 극 소량이 검출되며 전환율과 다른 생성가스에 거의 영 향을 미치지 않는다.

Water gas shift

$\mathrm{CO}+\mathrm{H}_{2} \mathrm{O} \rightleftharpoons \mathrm{CO}_{2}+\mathrm{H}_{2}$

Boudouard reaction

$2 \mathrm{CO} \rightleftharpoons \mathrm{CO}_{2}+\mathrm{C}$ 
식 (2)와 (3)에서 생성된 $\mathrm{CO}$ 와 $\mathrm{CO}_{2}$ 는 식 (6)과 (7) 로 인해 반응하게 된다. $\mathrm{H}_{2}$ 생산에 유용하게 쓰이는 식 (6)의 Water gas shift 반응으로 $\mathrm{CO}$ 가 소비되고 $\mathrm{CO}_{2}$ 가 증가하게 되며 $\mathrm{H}_{2}$ 가 생성된다. 식 (7)은 2개의 $\mathrm{CO}$ 가 소비되어 $\mathrm{CO}_{2}$ 와 $\mathrm{C}$ 가 되는 Boudouard reaction 으로 $\mathrm{H}_{2}$ 생성량과 전환율에 관계없이 $\mathrm{CO}, \mathrm{CO}_{2}$ 의 생 성량이 변한다.

Fig. 3, 4, 5의 전환율이 $100 \%$ 에 도달한 $700^{\circ} \mathrm{C}$ 이 상의 고온 영역에서는 $\mathrm{H}_{2}$ 생성량의 수렴, $\mathrm{CO}$ 생성량 의 증가, $\mathrm{CO}_{2}$ 생성량의 감소가 공통적으로 관찰되며 비슷한 결과를 다른 문헌에서도 확인 할 수 있다 ${ }^{2021)}$. 고온 영역에서 전환율과 $\mathrm{H}_{2}$ 의 생성량이 일정하므로 식 (2)와 (3)의 반응도 일정한 비를 가지며 진행된다. 따라서 고온 영역에서의 $\mathrm{CO}$ 와 $\mathrm{CO}_{2}$ 생성량의 변화는 전환율에 영향을 주지 않는 식 (6)과 (7)에 의존하게 된다. 발열반응인 식 (6)과 (7)은 낮은 온도에서는 $\mathrm{CO}$ 를 소비하며 $\mathrm{CO}_{2}$ 를 생성하지만, 높은 온도에서는 $\mathrm{CO}$ 의 소비가 억제되거나 역반응이 진행되어 오히려 $\mathrm{CO}_{2}$ 를 소비한다 ${ }^{21,22)}$. 그러므로 Fig. $3,4,5$ 의 고온 영 역에서 $\mathrm{CO}_{2}$ 감소는 식 (6)과 (7)의 억제 및 역반응으 로 설명 할 수 있다. 그러나 식(6)은 전환율과 관계없 이 $\mathrm{H}_{2}$ 를 생성하게 되어 실험 결과와 맞지 않으므로 고온 영역에서는 식 (7) Boudouard reaction으로 인 해 $\mathrm{CO}$ 와 $\mathrm{CO}_{2}$ 의 생성량이 변할 것으로 추측된다.

\section{2 촉매의 열적, 물리적 특성}

촉진제 첨가에 따른 촉매의 변화와 탄소 침적 양 을 보기위해 $\mathrm{XRD}$ 와 TG 분석을 수행하여 Fig. 6에 나타내었다. Fig. 6 (a)는 각 촉매의 XRD 분석 결과 이다. $\mathrm{NiO}$ 의 peak는 $2 \theta=37,43,63,75,79^{\circ}$ 에서 확 인되며, $2 \theta=37^{\circ}$ 에서 Scherrer equation을 이용하여 $\mathrm{Ni}$ 의 입자 크기를 계산하였다.

$\mathrm{Ni}$ 입자 크기는 촉매 활성과 탄소 침적에 영향을 주게 되어 매우 중요하다 ${ }^{18)}$. 동일 양의 $\mathrm{Ni}$ 가 담지 되

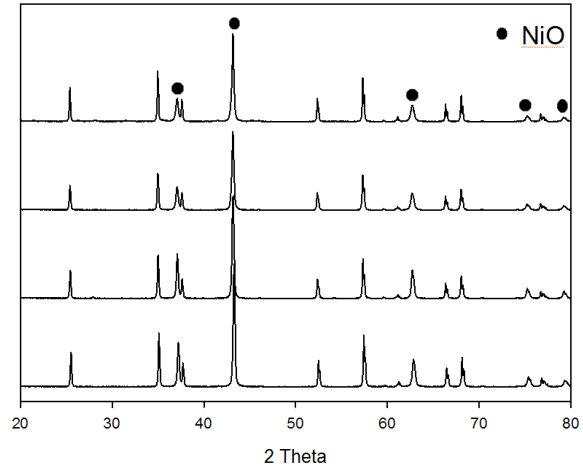

(a)

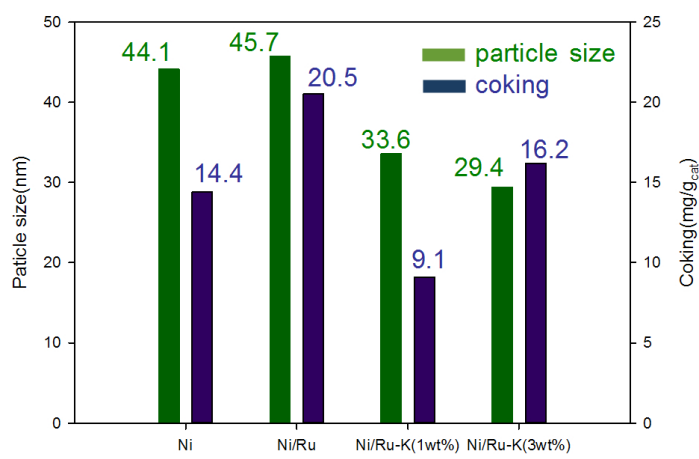

(b)

Fig. 6 (a) XRD of fresh catalysts (b) Ni particle size and amount of coking on each catalyst

었을 때 입자 크기가 작을수록 $\mathrm{Ni}$ 의 분산도가 증가 하여 촉매 활성이 좋아지게 되며 이는 곧 탄소 침적 에도 영향을 주게 된다 ${ }^{18)}$. Fig. 6 의 $\mathrm{Ni} / \mathrm{Al}_{2} \mathrm{O}_{3}$ 촉매와 $\mathrm{Ni} / \mathrm{Ru} / \mathrm{Al}_{2} \mathrm{O}_{3}$ 촉매의 $\mathrm{Ni}$ 입자 크기는 각각 $44.1 \mathrm{~nm}$ 와 $45.7 \mathrm{~nm}$ 로 거의 비슷한 값을 보인다. 이와 달리 $\mathrm{K}$ 를 첨가한 $\mathrm{Ni} / \mathrm{Ru}-\mathrm{K}(1 / 3 \mathrm{wt} \%) / \mathrm{Al}_{2} \mathrm{O}_{3}$ 촉매는 각각 $33.6 \mathrm{~nm}$ 와 $29.4 \mathrm{~nm}$ 로 $\mathrm{Ni} / \mathrm{Al}_{2} \mathrm{O}_{3}$ 촉매와 $\mathrm{Ni} / \mathrm{Ru} / \mathrm{Al}_{2} \mathrm{O}_{3}$ 촉매에 비해 $\mathrm{Ni}$ 입자 크기가 크게 줄어든 것이 관찰된다. 앞 선 실험 결과와 함께 고려해보면, $\mathrm{Ru}$ 의 첨가로 인한 촉매 활성 증가는 $\mathrm{Ni}$ 입자 크기의 큰 변화가 없으므 로 $\mathrm{Ru}$ 이 $\mathrm{Ni}$ 에 직접 영향을 주기보다는 귀금속 촉매 에 쓰이는 $\mathrm{Ru}$ 의 높은 활성으로 인한 것으로 판단된 다. 반대로 $\mathrm{K}$ 의 경우, 촉진제로써 $\mathrm{Ni}$ 입자 크기를 줄 이고 분산도를 증가시켜 높은 촉매 활성을 보인 것 
으로 생각된다. 결과적으로 가장 작은 $\mathrm{Ni}$ 입자 크기 를 가진 $\mathrm{Ni} / \mathrm{Ru}-\mathrm{K}(3 \mathrm{wt} \%) / \mathrm{Al}_{2} \mathrm{O}_{3}$ 촉매가 앞선 톨루엔 수증기 개질에서 가장 좋은 활성을 보인 것을 설명 해준다.

동일한 조건, 시간동안 톨루엔 수증기 개질 후 회수 한 각 촉매별 탄소 침적양은 $14.4 \mathrm{mg} / \mathrm{g}_{\mathrm{cat}}, 20.5 \mathrm{mg} / \mathrm{g}_{\mathrm{cat}}$, $9.1 \mathrm{mg} / \mathrm{g}_{\mathrm{cat}}, 16.2 \mathrm{mg} / \mathrm{g}_{\mathrm{cat}}$ 이다. 촉진제 첨가에 따른 경향 성은 보이지 않으며 오히려 $\mathrm{Ni} / \mathrm{Al}_{2} \mathrm{O}_{3}$ 촉매가 $\mathrm{Ni} / \mathrm{Ru}$ / $\mathrm{Al}_{2} \mathrm{O}_{3}$ 촉매와 $\mathrm{Ni} / \mathrm{Ru}-\mathrm{K}(3 \mathrm{wt} \%) / \mathrm{Al}_{2} \mathrm{O}_{3}$ 촉매보다 더 적 은 탄소 침적양을 보여준다. 그러나 탄소 침적은 전 환율에 영향을 받으므로 ${ }^{15)}$ 전환율이 유사한 촉매와 비교해야 한다. 전환율 $100 \%$ 에 도달하였던 $\mathrm{Ni} / \mathrm{Ru} /$ $\mathrm{Al}_{2} \mathrm{O}_{3}$ 촉매와 $\mathrm{Ni} / \mathrm{Ru}-\mathrm{K}(1 / 3 \mathrm{wt} \%) / \mathrm{Al}_{2} \mathrm{O}_{3}$ 촉매를 비교해 보면 $\mathrm{Ni} / \mathrm{Ru} / \mathrm{Al}_{2} \mathrm{O}_{3}$ 촉매보다 $\mathrm{Ni} / \mathrm{Ru}-\mathrm{K}(1 / 3 \mathrm{wt} \%) / \mathrm{Al}_{2} \mathrm{O}_{3}$ 촉매에서 적은 양의 탄소 침적이 관찰되며 $\mathrm{K}$ 의 첨가 로 인해 탄소 침적이 억제된 것으로 판단된다. 따라 서 톨루엔 수증기 개질에서 확인된 $\mathrm{K}$ 의 첨가에 따른 촉매 활성 향상과 탄소 침적에 대한 저항성을 확인 할 수 있으며, 특히 $\mathrm{Ni} / \mathrm{Ru}-\mathrm{K}(1 \mathrm{wt} \%) / \mathrm{Al}_{2} \mathrm{O}_{3}$ 촉매는 $\mathrm{Ni} / \mathrm{Ru}-\mathrm{K}(3 \mathrm{wt} \%) / \mathrm{Al}_{2} \mathrm{O}_{3}$ 촉매보다 낮은 온도 영역의 톨 루엔 수증기 개질 시 성능이 저조하지만 탄소 침적 에 대한 저항성이 더 좋은 것이 확인되었다.

\subsection{Activation energy}

Fig. 2와 5의 결과를 이용하여 $\mathrm{Ni}$ 촉매와 $\mathrm{Ni} / \mathrm{Ru}-\mathrm{K}$ $(3 \mathrm{wt} \%) / \mathrm{Al}_{2} \mathrm{O}_{3}$ 촉매의 톨루엔 수증기 개질에서의 활 성화에너지 $\left(\mathrm{E}_{\mathrm{a}}\right)$ 를 계산하였다. 전체 톨루엔 수증기 개질을 일차반응으로 가정하고 plug-flow로 계산하 였다).

$$
\begin{aligned}
& r=k C_{\text {tar }} \\
& \ln k=\ln \left(-\frac{\ln \left(1-X_{c}\right)}{\tau}\right)=-\frac{E_{a}}{R} \frac{1}{T}+A
\end{aligned}
$$

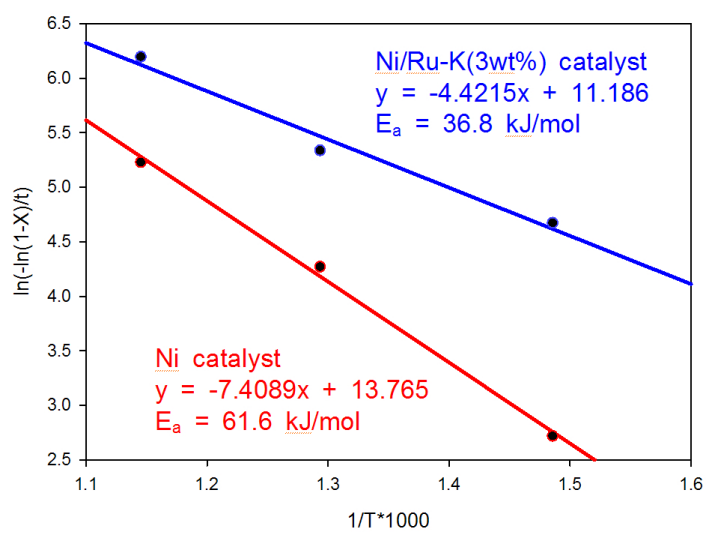

Fig. 7 Arrhenius plot of $\mathrm{Ni}$ and $\mathrm{Ni} / \mathrm{Ru}-\mathrm{K}(3 \mathrm{wt} \%)$ catalysts

식 (9)의 $\tau$ 는 space time으로 $\mathrm{V}_{\text {catalyst }} /$ Flow 로 계산 하였다. 식 (8)과 (9)를 사용하여 $\mathrm{Ni} / \mathrm{Al}_{2} \mathrm{O}_{3}$ 촉매와 $\mathrm{Ni}$ / $\mathrm{Ru}-\mathrm{K}(3 \mathrm{wt} \%) / \mathrm{Al}_{2} \mathrm{O}_{3}$ 촉매의 Arrhenius plot을 Fig. 7에 나타내었다. 여러 문헌에서 Ni-base 촉매와 상용촉매 등을 사용하여 톨루엔 수증기 개질의 $\mathrm{E}_{\mathrm{a}}$ 를 계산하고 $58 \mathrm{~kJ} / \mathrm{mol}, 109 \mathrm{~kJ} / \mathrm{mol}$ 등의 값을 제시하였다,12). 본 연구에서 $\mathrm{Ni} / \mathrm{Al}_{2} \mathrm{O}_{3}$ 촉매의 $\mathrm{E}_{\mathrm{a}}$ 는 $61.6 \mathrm{~kJ} / \mathrm{mol}$ 로 문헌의 $\mathrm{E}_{\mathrm{a}}$ 값과 유사하며) 톨루엔 수증기 개질에서 활성이 좋았던 $\mathrm{Ni} / \mathrm{Ru}-\mathrm{K}(3 \mathrm{wt} \%) / \mathrm{Al}_{2} \mathrm{O}_{3}$ 촉매의 $\mathrm{E}_{\mathrm{a}}$ 는 $36.8 \mathrm{~kJ} / \mathrm{mol}$ 이다. 이는 Fig. 2 와 5 의 결과에서 보인바와 같이 $\mathrm{Ni} / \mathrm{Al}_{2} \mathrm{O}_{3}$ 촉매보다 $\mathrm{Ni} / \mathrm{Ru}-\mathrm{K}(3 \mathrm{wt} \%) / \mathrm{Al}_{2} \mathrm{O}_{3}$ 촉매가 톨 루엔 수증기 개질에서 더 효과적임을 나타냈다.

\section{4. 결 론}

톨루엔 수증기 개질 촉매 제작을 위해 $\mathrm{Ru}$ 와 $\mathrm{K}$ 를 촉진제로 첨가하여 $\mathrm{Ni} / \mathrm{Al}_{2} \mathrm{O}_{3}, \mathrm{Ni} / \mathrm{Ru} / \mathrm{Al}_{2} \mathrm{O}_{3}, \mathrm{Ni} / \mathrm{Ru}-\mathrm{K}$ $(1 / 3 \mathrm{wt} \%) / \mathrm{Al}_{2} \mathrm{O}_{3}$ 촉매를 각각의 함량에 맞춰 제작하 였다. 톨루엔 수증기 개질 시 각 촉매에서 온도 상승 과 함께 전환율과 생성가스 내 $\mathrm{H}_{2}$ 생성량의 증가가 관찰되었고 $\mathrm{Ru}$ 와 $\mathrm{K}$ 첨가로 인한 촉매 활성의 증가 가 확인되었다. $\mathrm{Ni} / \mathrm{Ru}-\mathrm{K}(3 \mathrm{wt} \%) / \mathrm{Al}_{2} \mathrm{O}_{3}$ 촉매는 저온에 서 높은 활성과 $700^{\circ} \mathrm{C}$ 에서 전환율 $100 \%$ 에 도달하며 본 연구에서 가장 좋은 활성을 보였다. 고온 영역에 
서 생성가스 내 $\mathrm{CO}, \mathrm{CO}_{2}$ 생성량의 변화는 Boudouard reaction의 영향을 받는 것으로 판단된다. XRD 분석 을 통해 $\mathrm{K}$ 의 $\mathrm{Ni}$ 입자 크기에 대한 영향으로 $\mathrm{Ni}$ 입자 크기가 작아진 것을 확인하였으며 $\mathrm{TG}$ 분석을 통해 $\mathrm{Ni} / \mathrm{Ru}-\mathrm{K}(1 \mathrm{wt} \%) / \mathrm{Al}_{2} \mathrm{O}_{3}$ 촉매가 $9.1 \mathrm{mg} / \mathrm{g}_{\mathrm{cat}}$ 으로 가장 탄 소 침적양이 적은 것을 확인하였다. $\mathrm{Ni} / \mathrm{Al}_{2} \mathrm{O}_{3}, \mathrm{Ni} / \mathrm{Ru}-\mathrm{K}$ $(3 \mathrm{wt} \%) / \mathrm{Al}_{2} \mathrm{O}_{3}$ 촉매의 $\mathrm{E}_{\mathrm{a}}$ 값은 Arrhenius plot을 이용 하여 계산하였으며 각각 $61.6 \mathrm{~kJ} / \mathrm{mol}, 36.8 \mathrm{~kJ} / \mathrm{mol}$ 로 $\mathrm{Ni} / \mathrm{Ru}-\mathrm{K}(3 \mathrm{wt} \%) / \mathrm{Al}_{2} \mathrm{O}_{3}$ 촉매가 톨루엔 수증기 개질에 서 더 높은 활성을 보였다.

\section{References}

1. j. Ashok, S. Kawi, "Steam Reforming of Toluene As A Biomass Tar Model Compound Over $\mathrm{CeO}_{2}$ promoted $\mathrm{Ni} / \mathrm{CaO}-\mathrm{Al}_{2} \mathrm{O}_{3}$ Catalytic System", International Journal of Hydrogen Energy, Vol. 38, 2013, p. I3938-I3949.

2. M. W. Seo, J. H. Kim, S. H. Lee, "Introduction and Current Status of Biomass Gasification Downstream Processing", KIC News, Vol. 15, No. 6, 2012, p. 39-53.

3. S. J. Yoon, Y. G. Son, Y. G. Kim, J. G. Lee, "Removal of Tar and Soot in The Syngas Produced from Gasification of Wood Chip by Using Catalytic Reformer", Trans. of the Korean Hydrogen and New Energy Society, Vol. 20, No. 6, pp. 519-525.

4. S. J. Yoon, Y. C. Choi, J. G. Lee, "Hydrogen Production from Biomass Tar by Catalytic Steam Reforming”, Energy Conversion and Management, Vol. 51, 2010, p. 42-47.

5. S. J. Yoon, J. G. Lee, H. W. Ra, M. W. Seo, "Supercritical Water Gasification of Low Rank Coal with High Moisture Content", Trans. of the Korean Hydrogen and New Energy Society, Vol. 24, No. 4, 2013, pp. 340 346.

6. D. I. Kim, J. G. Lee, Y. K. Kim, S. J. Yoon,
"The Characteristics of Coal Gasification using Microwave Plasma", Trans. of the Korean Hydrogen and New Energy Society, Vol. 23, No. 1, 2012, pp. 93-99.

7. J. Tao, L. Zhao, C. Dong, Qiang Lu, X. Du, E. Dahlquist, "Catalytic Steam Reforming of Toluene as a Model Biomass Gasification Tar Compound using Ni-CeO ${ }_{2} / \mathrm{SBA}-15$ Catalysts", Energies, Vol. 6, 2013, p. 3284-3296.

8. R. Yin, R. Liu, J. Wu, X. Wu, C. Sun, C. Wu, "Influence of Particle Size on Performance of a Pilot-Scale Fixed-Bed Gasification System", Bioresource Technol, Vol. 119, 2012, p. 15-21.

9. G. Guan, G. Chen, Y. Kasai, E. W. C. Lim, X. Hao, M. Kaewpanh, A. Abuliti, C. Fushimie, A. Tsutsumi, "Catalytic Steam Reforming of Biomass Tar over Iron- or Nickel-based Catalyst Supported on Calcined Scallop Shell", Applied Catalysis B: Environmental, Vol. 115-116, 2012, p. 159-168.

10. S. J. Yoon, Y. K. Kim, J. G. Lee, "Catalytic Oxidation of Biomass Tar over Platinum and Ruthenium Catalysts", Industrial and Engineering Chemistry Research, Vol. 50, 2011, p. 2445-2451.

11. D. Swierczynski, S. Libs, C. Courson, A. Kiennemann, "Steam Reforming of Tar from a Biomass Gasification Process over Ni/Olivine Catalyst using Toluene as a Model Compound", Applied Catalysis B: Environmental, Vol. 74, 2007, p. 211-222.

12. U. Oemar, A. M. Li, K. Hidajat, S. Kawi, "Mechanism and Kinetic Modeling for Steam Reforming of Toluene on $\mathrm{La}_{0.8} \mathrm{Sr}_{0.2} \mathrm{Ni}_{0.8} \mathrm{Fe}_{0.2} \mathrm{O}_{3}$ Catalyst", AIChE Journal, Vol. 00, No. 00, 2014.

13. M. Asadullah, S. Ito, K. Kunimori, M. Yamada, K. Tomishige, "Biomass Gasification to Hydrogen and Syngas at Low Temperature: Novel Catalytic System using Fluidized-Bed Reactor", Journal of Catalysis, Vol. 208, 2002, p. 255-259.

14. D. L. Trimm, "Catalysts for the Control of Coking during Steam Reforming", Catalysis Today, Vol. 
49, 1999, p. 3-10.

15. U. Oemar, M.L. Ang, W.F. Hee, K. Hidajat, S. Kawi, "Perovskite $\mathrm{La}_{\mathrm{x}} \mathrm{M}_{1-\mathrm{x}} \mathrm{N}_{\mathrm{i} 0.8} \mathrm{Fe}_{0.2} \mathrm{O}_{3}$ cAtalyst for Steam Reforming of Toluene: Crucial Role of Alkaline Earth Metal at Low Steam Condition", Applied Catalysis B: Environmental, Vol. 148149, 2014, p. 231-242.

16. F. M. Josuinkas, C. P. B. Quitete, N. F. P. Ribeiro, M. M. V. M. Souza, "Steam Reforming of Model Gasification Tar Compounds over Nickel Catalysts Prepared from Hydrotalcite Precursors", Fuel Processing Technology, Vol. 121, 2014, p. 76-82.

17. G. Garbarino, E. Finocchio, A. Lagazzo, I. Valsamakis, P. Riani, V. S. Escribano, Guido Busca, "Steam Reforming of Ethanol-Phenol Mixture on $\mathrm{Ni} / \mathrm{Al}_{2} \mathrm{O}_{3}$ : Effect of Magnesium and Boron on Catalytic Activity in the Presence and Absence of Sulphur", Applied Catalysis B: Environmental, Vol. 147, 2014, p. 813-826.

18. C. P. B. Quitete, R. C. P. Bittencourt, M. M. V. M. Souza, "Steam Reforming of Tar using Toluene as a Model Compound with Nickel Catalysts
Supported on Hexaaluminates", Applied Catalysis A: General, Vol. 478, 2014, p. 234-240.

19. P. N. Bhandari, A. Kumar, D. D. Bellmer, R. L. Huhnke, "Synthesis and Evaluation of BiocharDerived Catalysts for Removal of Toluene (Model Tar) from Biomass-Generated Producer Gas", Renewable Energy, Vol. 66, 2014, p. 346-353.

20. A. Łamacz, A. Krzton, G. Djega-Mariadassou, "Steam Reforming of Model Gasification Tars Compounds on Nickel Based Ceria-Zirconia Catalysts", Catalysis Today, Vol. 176, 2011, p. 347-351.

21. C. K. Acharya, F. Jiang, C. H. Liao, P. Fitzgerald, K. S. Vecchio, R. J. Cattolica, "Tar and $\mathrm{CO}_{2}$ Removal from Simulated Producer Gas with Activated Carbon and Charcoal", Fuel Processing Technology, Vol. 106, 2013, p. 201-208.

22. B. L. Augusto, L. O.O. Costa, F. B. Noronha, R. C. Colman, L. V. Mattos, "Ethanol Reforming over Ni/CeGd Catalysts with Low Ni Content", International Journal of Hydrogen Energy, Vol. 37, 2012, p. I2258-I2270. 